\title{
Factors Afferting the Hydrogen Environment Assisted Cracking Resistance of an NI-Zn-Mg-(Cu) Alloy
}

\author{
G.A. Young, J.R. Scully
}

This report was prepared ar an ammunt of work sponsored by the United States Government. Neither the United States. nn the I Inited States Department of Energy, nor any of their employees, nor any of thair...m-n.m.tors, subcontractors, or their employees, makes any warranty, express or implied, or assı or usefulness of any informa 4 ... nparatus, product or process disclosed, or represents that its use would not infringe privatalv owned rights. 


\title{
Factors Affecting the Hydrogen Environment Assisted Cracking Resistance of an Al-Zn-Mg-(Cu) Alloy
}

\author{
George A. Young ${ }^{\dagger}$ and John R. Scully \\ Center for Electrochemical Science and Engineering \\ Department of Materials Science \\ University of Virginia \\ Charlottesville, VA 22903-2442 \\ ${ }^{t}$ Present Address: Lockheed Martin Corporation \\ P.O. Box 1072, Schenectady, NY 12301-1072
}

Precipitation hardenable $\mathrm{Al}-\mathrm{Zn}-\mathrm{Mg}$ alloys are susceptible to hydrogen environment assisted cracking (HEAC) when exposed to aqueous environments. In $\mathrm{Al}-\mathrm{Zn}-\mathrm{Mg}-\mathrm{Cu}$ alloys, overaged tempers are used to increase HEAC resistance at the expense of strength but overaging has little benefit in low copper alloys. However, the mechanism or mechanisms by which overaging imparts HEAC resistance is poorly understood. The present research investigated hydrogen uptake, diffusion, and crack growth rate in $90 \%$ relative humidity (RH) air for both a commercial copper bearing $\mathrm{Al}-\mathrm{Zn}-\mathrm{Mg}-\mathrm{Cu}$ alloy (AA 7050) and a low copper variant of this alloy in order to better understand the factors which affect HEAC resistance. Experimental methods used to evaluate hydrogen concentrations local to a surface and near a crack tip include nuclear reaction analysis (NRA), focused ion beam, secondary ion mass spectroscopy (FIB/SIMS) and thermal desorption spectroscopy (TDS).

Results show that overaging the copper bearing alloys both inhibits hydrogen ingress from oxide covered surfaces and decreases the apparent hydrogen diffusion rates in the metal. When freshly bared coupons of AA 7050 are exposed to $90^{\circ} \mathrm{C}, 90 \% \mathrm{RH}$ air, hydrogen ingress follows inverselogarithmic-type kinetics and is equivalent for underaged (HEAC susceptible) and overaged (HEAC resistant) tempers. However, when the native oxide is allowed to form $\left(24 \mathrm{hrs}\right.$ in $25^{\circ} \mathrm{C}$, $40 \% \mathrm{RH}$ lab air) prior to exposure to $90^{\circ} \mathrm{C}, 90 \% \mathrm{RH}$ air, the overaged alloy shows significantly less hydrogen ingress than the underaged alloy. Humid air is a very aggressive environment capable of producing near surface $(\sim 1 \mu \mathrm{m})$ hydrogen concentrations in excess of $10,000 \mathrm{wt}$. ppm at $90^{\circ} \mathrm{C}$. In the copper bearing alloy, overaging also decreases the apparent diffusivity of hydrogen. As AA 7050 is aged from underaged $\rightarrow$ peak aged $\rightarrow$ overaged, the activation energies for hydrogen diffusion and stage II ( $K$-independent) crack growth increase and the apparent diffusivity of hydrogen and stage II crack growth rate decrease. In the low copper alloy, overaging has little effect on hydrogen diffusion or crack growth kinetics. Comparison of the apparent activation energies for hydrogen diffusion and for $K$ independent (stage II) crack growth rate in $90 \% \mathrm{RH}$ air between 25 and $90^{\circ} \mathrm{C}$ indicates that hydrogen transport kinetics are responsible for the decreased crack growth rate of overaged AA 7050 relative to the peak aged temper.

\section{Introduction}

High strength aluminum alloys, including precipitation hardenable $\mathrm{Al}-\mathrm{Zn}-\mathrm{Mg}$ alloys are susceptible to hydrogen environment assisted cracking (HEAC) when exposed to aqueous environments [1-5]. In $\mathrm{Al}-\mathrm{Zn}-\mathrm{Mg}-\mathrm{Cu}$ alloys, overaged tempers are commonly used to increase HEAC resistance at the expense of strength but overaging has little benefit in low copper alloys 
[1-5]. However, the mechanism or mechanisms by which overaging imparts HEAC resistance is poorly understood [3]. The present research investigated hydrogen uptake, diffusion, and crack growth rate in $90 \%$ relative humidity $(\mathrm{RH})$ air for both a commercial copper bearing $\mathrm{Al}$ $\mathrm{Zn}-\mathrm{Mg}-\mathrm{Cu}$ alloy (AA 7050) and a low copper variant of this alloy in order to better understand the factors which affect HEAC resistance.

\section{Materials and Heat Treatments}

\section{Experimental Procedure}

The AA 7050 and the low copper variant of AA 7050 were supplied by the Aluminum Company of America (Alcoa) in final heat-treated form. The chemical composition of each material is given in Table 1. The AA 7050 material was heat-treated from a commercially produced 6" thick plate and the low copper material was from a 2" thick plate produced at the Alcoa Technical Center. Samples were taken from the T/4 plane of the 6" AA 7050 plate and the T/2 plane of the 2" thick low copper material. The heat treatments investigated include the underage (UA), peak aged (PA) and overaged (OA) tempers and are summarized in Table 2. The precipitation sequence in AA 7050 is Supersaturated Solid Solution $\rightarrow$ G.P. Zones $\rightarrow \eta^{\prime} \rightarrow \eta$ where $\eta^{\prime}$ is a metastable precipitate and $\eta$ is the equilibrium phase $\left(\mathrm{MgZn}_{2}\right)$ [6-9].

The microstructure of AA 7050 and the low copper variant are shown in Figure 1. The microstructure contained a combination of recrystallized and unrecrystallized grains. Typical dimensions of the pancake shaped, unrecrystallized grains are approximately $1000 \mu \mathrm{m}(\mathrm{L}) \times 250$ $\mu \mathrm{m}(\mathrm{T}) \times 75 \mu \mathrm{m}(\mathrm{S})$. Note the similar grain structure and degree of recrystallization for the AA 7050 and the low copper material. Note that the peak aged thermal treatment actually produced a slightly overaged microstructure in the low copper alloy. However, to facilitate the discussion, the term "peak aged" will be used to describe both the AA 7050 and the low copper alloy that was processed at the $154^{\circ} \mathrm{C}, 12$ hour thermal treatment.

\section{Environmental Exposure to Humid Air}

Hydrogen charging of the samples used in this study was performed via exposure to $90 \% \mathrm{RH}$ at temperatures between 25 and $90^{\circ} \mathrm{C}$. Temperature and humidity were electronically controlled in an environmentally sealed cabinet. The source of water vapor was distilled deionized water, while the source of air was laboratory air with low levels of $\mathrm{NO}_{\mathrm{x}}$ and $\mathrm{SO}_{\mathrm{x}}$. Details of the crack growth rate testing have been presented previously $[5,10]$.

\section{Analysis of Local Hydrogen Concentrations}

Nuclear Reaction Analysis (NRA)

Nuclear reaction analysis for hydrogen concentration measurements was performed via the

${ }^{15} \mathrm{~N}(\mathrm{p}, \alpha \gamma){ }^{12} \mathrm{C}$ resonance reaction. The NRA tests were performed in a vacuum chamber with a total pressure of $<1.3 \times 10^{-3} \mathrm{~Pa}$, with beam acceleration in excess of $6.385 \mathrm{MeV}$. The spot size of the beam was approximately $3 \mathrm{~mm}$ in diameter and the depth resolution was approximately 4 $\mathrm{nm}$. Depth profiling between $0-1 \mu \mathrm{m}$ was achieved by varying the energy of the ${ }^{15} \mathrm{~N}$ beam at a constant fluence such that the resonant energy was achieved at increasing depths. NRA was performed on both unstressed coupons $(-2.5 \mathrm{~cm} \mathrm{x} 2.5 \mathrm{~cm} \mathrm{x} 1 \mathrm{~cm})$ exposed to $25^{\circ} \mathrm{C}, 90 \% \mathrm{RH}$ air and on samples sectioned from the fracture surfaces of crack growth rate tests conducted in $90^{\circ} \mathrm{C}$, $90 \%$ RH air. 
Secondary Ion Mass Spectroscopy (SIMS)

A liquid gallium sputtering source was used to perform the SIMS depth profiles. The gallium beam was focused to $10 \times 10 \mu \mathrm{m}$ area at a current of $1000 \mathrm{pA}$ in order to examine a single grain facet. Depth profiling was performed in each of these regions from approximately $0-1$ micron into the surface. Sputtering depth was determined via known sputtering rates for aluminum. The hydrogen signal (mass/charge $=1$ ) was monitored with a quadrupole mass spectrometer. Three distinct areas of fracture surfaces from crack growth rate tests were investigated, the precrack, the near crack tip HEAC region $(\sim 5 \mathrm{~mm}$ from the crack tip on a single grain facet) and the fast fracture region. These areas were chosen to correspond to the position of NRA depth profiles as shown schematically in Figure 2. Note that for both NRA and SIMS, hydrogen charged samples were stored in liquid nitrogen for long term storage ( $>3$ days) or dry ice for short term storage.

\section{Hydrogen Diffusion and Trapping}

\section{Material and Hydrogen Charging}

The specimens used for diffusion and trapping studies were $1.6 \mathrm{~mm}$ diameter $\mathrm{x} 25 \mathrm{~mm}$ long rods machined from the T/4 position of the AA 7050 plate and the T/2 position of the low copper alloy. Hydrogen was charged into the samples via exposure to hot moist air $40^{\circ} \mathrm{C}, 90 \% \mathrm{RH}$ for approximately 7 days. The exposure time ensured a uniform hydrogen concentration through the samples ( $C_{\text {Center }} \geq 90 \% C_{\text {Surface }}$ ) assuming that the effective diffusivity through the alloy was $\geq 1 \mathrm{x}$ $10^{-12} \mathrm{~m}^{2} / \mathrm{s}$ at $40^{\circ} \mathrm{C}$. After hydrogen charging and prior to testing, the sample surfaces were lightly ground with 600 grit abrasive paper, rinsed in acetone, and ultrasonically cleaned in high purity methanol. The time between removal from the charging environment and test initiation was less than ten minutes for isothermal tests and less than 20 minutes for the thermally ramped tests.

\section{Thermal Desorption Spectroscopy}

The thermal desorption spectroscopy (TDS) system used in these experiments has been described previously [10-13]. The TDS was used to determine the diffusivity of hydrogen via Equation 1 where $D$ is the diffusivity, $m$ is the initial slope of the hydrogen pressure decay transient, $l$ is the length of the sample, $\beta_{1}$ is the root of the Bessel function $J_{0}\left(\beta_{n}\right)=0$, and $d$ is the diameter of the sample. Note that the slope, $(\log d P) / d t$ is a flux, so the units of $\mathrm{m}$ are $1 / \mathrm{s}$ and the parameters $l$ and $d$ are lengths yielding $D$ in length ${ }^{2} / \mathrm{s}\left(e . g ., \mathrm{m}^{2} / \mathrm{s}\right)$. Details of the procedure to calculate the diffusivity are given elsewhere $[11,14-16]$.

$$
\mathrm{D}=\frac{2.3 \mathrm{~m}}{\left(\frac{\pi}{\mathrm{l}}\right)^{2}+\left(\frac{2 \beta_{1}}{\mathrm{~d}}\right)^{2}}
$$

Constant heating rate tests were performed in a similar manner to the isothermal tests described previously [11] with one notable difference. After lowering the specimen into the furnace, the sample was isolated from the low vacuum side of the TDS system, and the total background pressure was allowed to stabilize to a total pressure of $<1.3 \times 10^{-6} \mathrm{~Pa}$ before the temperature ramp was initiated. This total pressure corresponded to a hydrogen partial pressure of $<1.3 \times 10^{-7}$ $\mathrm{Pa}$. In all cases, this background pressure was achieved in less than 5 minutes to help ensure minimal outgassing of the specimen prior to the desorption test. 


\section{Results \\ Hydrogen Uptake in Unstressed Coupons}

The hydrogen concentration profiles from unstressed coupons of underaged and overaged AA 7050 that were exposed to $90^{\circ} \mathrm{C}, 90 \% \mathrm{RH}$ air are shown in Figure 3. In Figure 3, the top graph is for coupons that had the native oxide on the exposed face while the bottom graph is for coupons which had the native oxide mechanically ground off with 600 grit, silicon carbide abrasive paper immediately prior to exposure to $90^{\circ} \mathrm{C}, 90 \% \mathrm{RH}$ air. Note that the presence of the native oxide does not appear to hinder hydrogen ingress in the underaged alloy, but it does appear to prevent significant hydrogen uptake in the overaged alloy.

\section{Hydrogen Concentrations Near Stress Corrosion Cracks}

Both NRA and SIMS concentration depth profiles for an overaged AA 7050 sample are shown in Figure 4. Note that the depth profiles are perpendicular to the crack plane. Three different regions of crack wake were examined with each technique; (1) the precrack region (exposed to humid air for the longest time), (2) the hydrogen environment assisted cracking (HEAC) region, and (3) the fast fracture region which was only exposed to relatively dry $(\sim 20 \% \mathrm{RH})$ laboratory air. Note that the NRA and SIMS spectra show similar concentration vs. depth profiles for each region investigated. Similarly, TDS shows a consistent trend (Figure 5) of high hydrogen concentrations (i.e. the area under the desorption curves) in the precrack and HEAC regions and relatively low hydrogen concentrations in the fast fracture region and a region $1.2 \mathrm{~mm}$ from the fracture surface. Note that the TDS concentrations represent an average concentration of the very high near surface hydrogen concentration ( 50 atomic \%) extending to a depth of $\sim 1 \mu \mathrm{m}$ and the bulk hydrogen concentration $(\sim 0.005$ atomic $\%)$.

\section{Hydrogen Diffusion Measurements}

Results of the hydrogen diffusion measurements for AA 7050 and low copper alloy are summarized in Table 3 and shown graphically in Figure 6. Data for high purity aluminum are also shown for comparison [11]. Note the similarity in activation energy $(\sim 14-16 \mathrm{~kJ} / \mathrm{mol})$ for all tempers except the overaged AA 7050, which shows a larger activation energy $(\sim 32.7 \mathrm{~kJ} / \mathrm{mol})$.

\section{Thermal Desorption Spectroscopy}

Thermal desorption spectra from peak aged and overaged AA 7050 are compared in Figure 7. Additionally, hardness data from similarly heated (and subsequently fast quenched) samples are shown to illustrate the instability of the microstructure during the desorption experiments. At a heating rate of $10^{\circ} \mathrm{C} / \mathrm{minute}$, the microstructure is unstable at temperatures greater than $-300^{\circ} \mathrm{C}$ as shown by the rapid decline in hardness.

\section{Discussion}

\section{Unstressed Coupons Exposed to $90^{\circ} \mathrm{C}, 90 \% \mathrm{RH}-$ Effect of the Native Oxide}

As shown in Figure 3, hydrogen uptake occurs readily on the freshly abraded surfaces of both AA 7050-UA and AA 7050-OA. However, there appears to be a distinct difference in uptake when the native oxides of the underaged and overaged alloys are exposed to $90^{\circ} \mathrm{C}, 90 \% \mathrm{RH}$ air. In the underaged condition, uptake occurred readily and penetration distances were very similar to the ground surface as shown in Figure 3. However, in AA $7050 \mathrm{OA}$, the native oxide delayed hydrogen uptake and the concentration profile after 20 hours exposure was less than the ground surface after 2 minutes exposure. 
These results suggest that the nature of the passive film may change with temper. This idea has also been suggested by Puiggali et al. [17]. These researchers investigated the native oxide of AA 7010 (Al-6.12Zn-2.33Mg-1.60Cu) which is compositionally similar to AA 7050 (Al-6.09Zn$2.14 \mathrm{Mg}-2.19 \mathrm{Cu})$. Puiggali et al . found that the surface film consisted of two sub-layers; (1) an inner $\mathrm{Al}_{2} \mathrm{O}_{3}$ and (2) an outer $\mathrm{MgO}$ layer. Moreover, the chemical composition was related to the temper, i.e., the $\mathrm{Mg}$ content of the surface layer decreased and the $\mathrm{Al}$ content increased as the alloy was heat treated from an underaged temper to the overaged temper. These findings are consistent with the notion that $\mathrm{MgO}$ is not protective and water may react readily with $\mathrm{Mg}$ and $\mathrm{Al}$ to produce high fugacity hydrogen, while $\mathrm{Al}_{2} \mathrm{O}_{3}$ offers some protection before it hydrates and water can react with aluminum metal [18].

The magnitude of the hydrogen concentration produced near the surface exposed to $90^{\circ} \mathrm{C}, 90 \%$ $\mathrm{RH}$ is also notable. The NRA technique measured peak concentrations $\sim 20,000-25,000 \mathrm{wt}$. ppm ( $\sim 60-70$ atomic\%), consistent with a high hydrogen fugacity generated by the oxidation of aluminum. The fugacity required to produce $25,000 \mathrm{wt}$. ppm via Sievert's law $\left(<10^{25} \mathrm{~atm}\right)[10]$ is many orders of magnitude below the theoretical hydrogen fugacity of hydrogen produced when aluminum is oxidized to form $\mathrm{Al}_{2} \mathrm{O}_{3}\left(\sim 10^{62}\right.$ atm) [5].

\section{Kinetics of Hydrogen Uptake}

Integration of the hydrogen concentration vs. distance plots shown in Figure 3 illustrate the kinetics of hydrogen ingress. These data are shown in Figure 8. Note that data for both the underaged and overaged tempers fall on the same curve and that hydrogen absorption follows logarithmic-type kinetics. The hydrogen ingress rate (given by the derivative of this curve) follows inverse-logarithmic-type kinetics. The inverse-log-type kinetics implies that hydrogen ingress is not diffusion controlled $(\sqrt{t}$-type kinetics); instead hydrogen production via oxidation likely limits the ingress rate.

\section{Hydrogen Diffusion in Aluminum Alloys}

There are conflicting data for hydrogen diffusion in both aluminum [11] and in aluminum alloys. Available data for hydrogen diffusion in aluminum alloys are summarized in Table 4 . Although hydrogen diffusion data in aluminum alloys is limited, the present work can likely be compared to data on AA 7075-T6 (i.e. peak aged) because of their similar composition and microstructure.

The present work predicts a room temperature hydrogen diffusivity $\left(D_{\text {Apparent }}\right)$ in AA 7050 PA to be $\sim 3 \times 10^{-12} \mathrm{~m}^{2} / \mathrm{s}$. The apparent diffusivity in AA 7050-PA is $\sim 7 \mathrm{X}$ slower than that predicted for AA 7075 -T6 by Braun [19] and $\sim 17 \mathrm{X}$ faster than the diffusivity predicted by Gest and Troiano [20]. However, analysis of the experimental techniques of both Gest and Braun suggest that the Gest data may underpredict the diffusivity while the Braun data may overpredict it. Gest and Troiano investigated hydrogen diffusion in AA 7075-T6 (i.e., peak aged) via galvanostatic permeation and reported a diffusivity of $D=2 \times 10^{-13} \mathrm{~m}^{2} / \mathrm{s}$ at room temperature $[20,21]$. However, Gest also showed that their permeation fluxes were independent of foil thickness, indicating that the results are not diffusion controlled and that surface reactions may bias their data toward lower apparent diffusivities $[20,21]$. 
Braun et al. have also studied the diffusion of hydrogen in AA 7075-T6 via electrochemical permeation at $20^{\circ} \mathrm{C}$ and concluded that the diffusivity is approximately 100 times faster (i.e., 2.3$6.0 \times 10^{-11} \mathrm{~m}^{2} / \mathrm{s}$ ) than the data of Gest and Troiano [19]. However, Braun et al. also failed to show that their permeation experiments were volume diffusion controlled and they noted that localized corrosion of the permeation foils (pitting) occurred, despite the use of Pd-Ag coatings and a corrosion inhibitor $\left(\mathrm{NaNO}_{3}\right)$ in their electrolyte [19]. Either pitting or fast-path diffusion may have biased their diffusivities toward higher values of apparent diffusivity.

The diffusivity of hydrogen in other alloy systems is also controversial. Aluminum-lithium binary alloys have been studied by both Anyalebechi [16] and Nakashima et al. [22]. As shown in Table 4, the data of these researchers are in disagreement with large differences in the reported activation energies for hydrogen diffusion (18-19 kJ/mol versus $62.7 \mathrm{~kJ} / \mathrm{mol}$ for similar alloys). Note that the data of Onuchukwu on AA 1060 are likely erroneous since the surface conditions at the charging side of their permeation foils were non-uniform and the currents measured on the exit side of their foils were not dominated by the oxidation of hydrogen [23].

\section{Hydrogen Trapping in Aluminum Alloys}

The effect of solute atoms on hydrogen diffusion was investigated by Leger and Piercy who used internal friction experiments to quantify hydrogen trapping at copper and magnesium solute atoms in $\mathrm{Al}-\mathrm{Cu}$ and $\mathrm{Al}-\mathrm{Mg}$ binary alloys [24]. Their research indicates that these elements were relatively weak traps with binding energies of $<4.8$ and $<5.8 \mathrm{~kJ} / \mathrm{mol}$ for copper and magnesium, respectively. Other microstructural defects such as precipitates and dislocations may also act as hydrogen trap states.

Saitoh, Iijima, and co-workers have used tritium microautoradiography to investigate hydrogen trapping in high purity aluminum, Al-4 $\mathrm{Cu}$ mass\%, Al-1 $\mathrm{Mg}_{2} \mathrm{Si}$ mass\%, and an Al-6wt\%Zn$2 \mathrm{wt} \% \mathrm{Mg}$ alloy $[25,26]$. This technique has spatial resolution better than $0.1 \mu \mathrm{m}$. The microautoradiography work suggests that, in general, microstructural features with tensile elastic stress fields act as hydrogen traps while features with compressive elastic stress fields act as hydrogen repellers $[25,26]$. Guinier-Preston (GP) zones with compressive stress fields (the Al$\mathrm{Mg}_{2} \mathrm{Si}$ and the $\mathrm{Al}-\mathrm{Zn}-\mathrm{Mg}$ alloys) repel hydrogen while GP-zones with a tensile stress field (the Al-Cu alloy) act as hydrogen traps $[25,26]$. In each of these alloys, trapping was observed at dislocations introduced by cold work and at interfacial dislocations associated with tensile elastic stress fields (the $\theta$ /matrix interface in the Al-Cu alloy and the $\eta /$ matrix interface in the $\mathrm{Al}-\mathrm{Zn}$ $\mathrm{Mg}$ alloy). Additionally, no evidence of hydrogen trapping was found at either $\eta^{\prime}$ precipitates or grain boundaries in the $\mathrm{Al}-\mathrm{Zn}-\mathrm{Mg}$ alloy [26].

In the present study, hydrogen release from multiple trapping states was observed in both the peak aged and overaged alloys (Figure 7). Assuming that one desorption peak is associated with hydrogen release from the lattice, AA 7050-PA shows 2 trapping states and AA 7050-OA shows 3 trapping states. However, trap state identification and quantification is complicated by the microstructural instability of the alloys in the temperature regimes in which hydrogen release ( $T$ $>200^{\circ} \mathrm{C}$ ) occurs. Figure 7 shows that significant metallurgical changes (given by the change in hardness) occur at temperatures $>300^{\circ} \mathrm{C}$. Unfortunately, these metallurgical changes complicate identification and quantification of hydrogen trapping states. 


\section{Implications to Hydrogen Environment Assisted Crack Growth}

In copper bearing $7 \mathrm{XXX}$ series alloys, it is well established that overaging produces an increased resistance to crack growth in both liquid and gaseous water environments $[1,2,4,5,27,28]$. Without copper additions greater than $\sim 1$ wt. \% [4], overaging has little effect on crack growth kinetics. The findings of the present study can help explain these observations.

As shown in Figure 3, the native oxide on overaged AA 7050 retards hydrogen ingress (likely because the thicker $\mathrm{Al}_{2} \mathrm{O}_{3}$ oxide is more stable and prevents hydrogen production as discussed previously) for significantly longer times (little uptake after 20 hours) relative to the underaged temper (significant uptake after 2 minutes). The increased resistance of AA $7050 \mathrm{OA}$ to hydrogen ingress likely delays stress corrosion cracking (SCC) initiation and increases SCC incubation ${ }^{1}$ times. When freshly bared metal is present to react with water vapor and produce corrosion generated hydrogen, Figures 3 and 8 show little difference in the hydrogen uptake rates. In this case, analogous to SCC from a precrack with freshly bared metal, the increased resistance of the overaged temper is likely from the decrease in the apparent diffusivity of hydrogen [5]. Note that Figure 6 predicts that this benefit only occurs at temperatures $<200^{\circ} \mathrm{C}$. Additional support for the role of diffusion limiting crack growth kinetics comes from a comparison of the apparent activation energies for crack growth and hydrogen diffusion. For AA 7050, overaging produces a change in activation energy for crack growth in $90 \% \mathrm{RH}$ air and for hydrogen diffusion of approximately $16 \mathrm{~kJ} / \mathrm{mol}[5]$ as shown in Figure 9.

\section{Conclusions}

- Exposure of bare AA 7050 to $90^{\circ} \mathrm{C}, 90 \% \mathrm{RH}$ air produces near surface concentrations of hydrogen on the order of $20,000 \mathrm{wt}$. ppm ( 50 atomic $\%)$ within $1 \mu \mathrm{m}$ of the surface. These concentrations were observed in both crack wake samples and in unstressed coupons.

- When exposed to $90^{\circ} \mathrm{C}, 90 \% \mathrm{RH}$ air, hydrogen uptake is not impeded by the native oxide of underaged AA 7050, but it is impeded by the native oxide of the overaged temper.

- In copper bearing AA 7050, the overaged temper displayed an activation energy for hydrogen diffusion $\sim 2 \mathrm{x}$ greater than that of peak aged or underaged heat treatments $(\sim 33$ $\mathrm{kJ} / \mathrm{mol}$ vs. $16 \mathrm{~kJ} / \mathrm{mol}$ ). In the low copper alloy, overaging has little effect on either the activation energy or apparent diffusivity of hydrogen.

- Since near surface hydrogen concentrations and concentration profiles $(\sim 0-1 \mu \mathrm{m})$ are similar in crack wake samples from AA 7050-UA and AA 7050-OA, the enhanced cracking resistance of the overaged temper is, in part, due to the decreased diffusivity of hydrogen through the AA 7050-OA.

\footnotetext{
${ }^{\prime}$ Here, SCC incubation is defined as the time required to initiate crack growth from a fatigue precracked (but oxide covered) specimen.
} 


\section{References}

1. Hyatt, M.V. and M.O. Speidel, Stress-Corrosion Cracking of High-Strength Aluminum Alloys, Report No. D6-24840, Boeing, Seattle, WA, 1970.

2. Speidel, M.O., "Stress Corrosion Cracking of Aluminum Alloys", Met. Trans. A, Vol. 6A, p. 631-651, 1975.

3. Holroyd, N.J.H. and D. Hardie, "Strain-Rate Effects in the Environmentally Assisted Fracture of a Commercial High-Strength Aluminium Alloy (7049)", Corrosion Science, Vol. 21, p. 129-144, 1981.

4. Sarkar, B., M. Marek, and E.A. Starke, "The Effect of Copper Content and Heat Treatment on the Stress Corrosion Characteristics of Al-6zn-2Mg-X Cu Alloys", Met. Trans. A, Vol. 12A, p. 1939-1943, 1981.

5. Young, G.A. and J.R. Scully, "The Effects of Test Temperature, Temper, and Alloyed Copper on the Hydrogen-Controlled Crack Growth Rate of an Al-Zn-Mg-(Cu) Alloy", Met. Trans. A, Vol. accepted for publication2002.

6. Lorimer, G.W., Precipitation in Aluminum Alloys, in Precipitation Processes in Solids, K.C. Russell and H.I. Aaronson, editors, TMS-AIME, Niagara Falls, NY, p. 87-119, 1976.

7. Bigot, A., et al., "Tomographic Atom Probe Study of Age Hardening Precipitation in Industrial AlZnMgCu (7050) Alloy", Materials Science Forum, Vol. 217-222, p. 695700, 1996.

8. Cziraki, A., B. Fogarassy, and I. Gerocs, Solid State Reactions in Al-Zn-Mg-Cu Alloys, in Light Materials for Transportation Systems, N.J. Kim, editor, TMS, Kyongju, Korea, p. 391-405, 1993.

9. Staley, J.T., "Aging Kinetics of Aluminum Alloy 7050", Met. Trans., Vol. 5, p. 929-932, 1974.

10. Young, G.A., Hydrogen Environment Assisted Cracking of an Al-Zn-Mg- $(\mathrm{Cu})$ Alloy, Ph.D., University of Virginia, Charlottesville, 1999.

11. Young, G.A. and J.R. Scully, "The Diffusion and Trapping of Hydrogen in High Purity Aluminum", Acta Mat., Vol. 46, No. 18, p. 6337-6349, 1998.

12. Smith, S.W. and J.R. Scully, Hydrogen Trapping and its Correlation to the Hydrogen Embrittlement Susceptibility of Al-Li-Cu-Zr Alloys, in Hydrogen Effects in Metals, A.W. Thompson and N.R. Moody, editors, TMS, Moran, Wyoming, 1994.

13. Smith, S.W., Hydrogen Interactions and Their Correlation to the Hydrogen Embrittlement Susceptibility of Al-Li-Cu-Zr Alloys, Ph.D., University of Virginia, Charlottesville, 1995.

14. Hill, M.L. and E.W. Johnson, "The Diffusivity of Hydrogen in Nickel", Acta Met., Vol. 3, p. 566-571, 1955.

15. Outlaw, R.A., D.T. Petersen, and F.A. Schmidt, "Diffusion of Hydrogen in Large Grain Aluminum", Scripta Met., Vol. 16, p. 287-292, 1982.

16. Anyalebechi, P.N., "Hydrogen Diffusion in Al-Li Alloys", Met. Trans. B, Vol. 21B, p. 649-655, 1990.

17. Puiggali, M., et al., "Effect of Microstructure on Stress Corrosion Cracking of an Al-ZnMg-Cu Alloy", Corr. Sci., Vol. 40(4/5), p. 805-819, 1998.

18. Wefers, K. and C. Misra, Oxides and Hydroxides of Aluminum, Report, Alcoa Laboratories, Alcoa Center, 1987. 
19. Braun, R., H.-J. Schluter, H. Zuchner, and H. Buhl, Hydrogen Permeation Measurements in Aluminum Alloy Foils, in Hydrogen Transport and Cracking in Metals, A. Turnbull, editor, The Institute of Materials, Teddington, UK, p. 280-288, 1994.

20. Gest, R.J. and A.R. Troiano, Hydrogen Embrittlement and Stress Corrosion Cracking in Aluminum Alloys, in L'Hydrogene dans les Metaux, Editions Science et Industrie, Paris, p. 427-432, 1972.

21. Gest, R.J. and A.R. Troiano, "Stress Corrosion and Hydrogen Embrittlement in an Aluminum Alloy", Corrosion, Vol. 30(8), p. 274-279, 1974.

22. Nakashima, M., M. Saeki, Y. Aratono, and E. Tachikawa, "Diffusivity of Tritium in LiAl Alloys", J. Nucl. Mats, Vol. 116, p. 141-146, 1983.

23. Onuchukwu, A.I. and S. Trasatti, "Hydrogen Permeation into Aluminum alloy 1060 as a Result of Corrosion in Alkaline Medium. Basic Features of the Process", Electrochemica Acta, Vol. 33(10), p. 1425-1430, 1988.

24. Leger, M. and G.R. Piercy, "Internal Friction in Hydrogen-Charged Aluminium Alloys", Phil. Mag. A, Vol. 43(2), p. 337-385, 1981.

25. Saitoh, H., Y. Iijima, and K. Hirano, "Behavior of Hydrogen in Pure Aluminium, Al4 mass\% $\mathrm{Cu}$ and $\mathrm{Al}-1$ mass\% $\mathrm{Mg}_{2} \mathrm{Si}$ Alloys Studied by Tritium Electron Microautoradiography", Journal of Materials Science, Vol. 29, p. 5739-5743, 1994.

26. Iijima, Y., et al., "Hydrogen Trapping and Repelling in an Al-6wt\%Zn-2wt\%Mg Alloy", J. Mat. Sci., Vol. 27(21), p. 5735-5738, 1992.

27. Scamans, G.M., "Stress Corrosion Cracking of Aluminium Alloys by Hydrogen Embrittlement", Aluminium, Vol. 58, p. 332-334, 1982.

28. Holroyd, N.J.H., A.K. Vasudevan, and L. Christodoulou, Stress Corrosion of HighStrength Aluminum Alloys, in Aluminum Alloys-Contemporary Research and Applications, A.K. Vasudevan and R.D. Doherty, editors, Academic Press, New York, p. 463-483, 1989. 
Table 1. Chemical Composition of the Alloys Used in this Study (Weight Percent).

\begin{tabular}{ccccccccc}
\hline Alloy & $\mathbf{Z n}$ & $\mathbf{M g}$ & $\mathrm{Cu}$ & $\mathrm{Zr}$ & $\mathrm{Si}$ & $\mathbf{F e}$ & $\mathrm{Al}$ & $\begin{array}{c}\mathrm{Mg} / \mathrm{Zn} \\
\text { ratio }\end{array}$ \\
\hline AA 7050 (spec.) & $5.7-6.7$ & $1.9-2.6$ & $2.0-2.6$ & $.08-.15$ & 0.12 & 0.15 & Bal. & $0.28-0.45$ \\
\hline AA 7050 (meas.) & 6.09 & 2.14 & 2.19 & 0.11 & 0.05 & 0.09 & Bal. & 0.35 \\
\hline Low Cu 7050 (meas.) & 6.87 & 2.65 & 0.06 & 0.10 & 0.04 & 0.10 & Bal. & 0.38 \\
\hline
\end{tabular}

Table 2. Temper Designations and Heat Treatments.

\begin{tabular}{cc}
\hline Temper & Heat Treatment \\
\hline Underaged (UA or T3) & $467^{\circ} \mathrm{C} / 2 \mathrm{hrs}+$ Water Quench $+2 \%$ Stretch $+118^{\circ} \mathrm{C} / 4 \mathrm{hrs}$ \\
\hline Peak Aged (PA or T6) & 7050 -Underaged $+118^{\circ} \mathrm{C} / 20 \mathrm{hrs}+154^{\circ} \mathrm{C} / 12 \mathrm{hrs}$ \\
\hline Overaged (OA or T74) & 7050 -Underaged $+163^{\circ} \mathrm{C} / 27 \mathrm{hrs}$ \\
\hline
\end{tabular}

Table 3. Hydrogen Diffusion Measurements from Isothermal Desorption Experiments.

\begin{tabular}{cccccc}
\hline Material & $\begin{array}{c}\mathbf{D}_{0} \\
\left(\mathbf{m}^{2} / \mathbf{s}\right)\end{array}$ & $\begin{array}{c}\mathbf{9 5 \%} \text { Confidence } \\
\left(\mathbf{m}^{2} / \mathbf{s}\right)\end{array}$ & $\begin{array}{c}Q_{\text {Apparent }} \pm \mathbf{9 5 \%} \\
(\mathbf{k J} / \mathbf{m o l})\end{array}$ & $\begin{array}{c}\text { T Range } \\
\left.\text { Studied }{ }^{\circ} \mathrm{C}\right)\end{array}$ & $\begin{array}{c}D_{\text {Apparent }} \text { at 25 } \\
\left(\mathbf{m}^{2} / \mathbf{s}\right)\end{array}$ \\
\hline 99.999 wt.\% Al & $1.80 \times 10^{-8}$ & $1.19-2.57 \times 10^{-8}$ & $16.2 \pm 1.5$ & $25-600$ & $2.60 \times 10^{-11}$ \\
AA 7050-UA (T3) & $5.49 \times 10^{-9}$ & $0.15-2.0 \times 10^{-8}$ & $15.8 \pm 5.0$ & $150-250$ & $9.33 \times 10^{-12}$ \\
AA 7050-PA (T6) & $2.24 \times 10^{-9}$ & $0.89-5.64 \times 10^{-9}$ & $16.1 \pm 4.2$ & $150-400$ & $3.37 \times 10^{-12}$ \\
AA7050-OA (T74) & $1.70 \times 10^{-7}$ & $0.37-7.88 \times 10^{-7}$ & $32.7 \pm 6.7$ & $150-400$ & $3.15 \times 10^{-13}$ \\
Low Cu-PA & $2.65 \times 10^{-9}$ & $1.39-5.05 \times 10^{-9}$ & $14.2 \pm 2.5$ & $150-250$ & $8.59 \times 10^{-12}$ \\
Low Cu-OA & $3.24 \times 10^{-9}$ & $1.41-7.43 \times 10^{-9}$ & $14.2 \pm 3.2$ & $150-250$ & $1.05 \times 10^{-11}$ \\
\hline
\end{tabular}

Table 4. Summary Data for the Apparent Diffusivity of Hydrogen in Solid Aluminum Alloys.

\begin{tabular}{|c|c|c|c|c|c|c|}
\hline Material & $\begin{array}{c}\text { Temperature } \\
\text { Range }\left({ }^{\circ} \mathrm{C}\right) \\
\end{array}$ & $\begin{array}{c}\text { Experimental } \\
\text { Technique } \\
\end{array}$ & $\begin{array}{c}D_{0} \\
\left(\mathrm{~m}^{2} / \mathrm{s}\right)\end{array}$ & $\underset{(\mathrm{kJ} / \mathrm{mol})}{Q}$ & $\begin{array}{c}\text { Diffusivity } \\
\text { At } 20^{\circ} \mathrm{C}\left(\mathrm{m}^{2} / \mathrm{s}\right)\end{array}$ & Reference \\
\hline 1060 & 20 & Permeation & $\ldots$ & -- & $2.4 \times 10^{-10}$ & {$[23]$} \\
\hline AA $7075-\mathrm{T} 6$ & 20 & Galvanostatic Permeation & $\cdots$ & $\ldots$ & $2 \times 10^{-13}$ & [20] \\
\hline $\begin{array}{l}2024-\mathrm{T} 3 \\
7075-\mathrm{T} 6 \\
7076-\mathrm{T} 6 \\
7075-\mathrm{T} 6 \\
\end{array}$ & $\begin{array}{l}20 \\
20 \\
20 \\
20\end{array}$ & $\begin{array}{c}\text { Potentiostatic Permeation } \\
\text { Galvanostatic Permeation } \\
\text { Potentiostatic Permeation } \\
\text { Current Pulse }\end{array}$ & $\begin{array}{l}-\cdots \\
\cdots- \\
\cdots- \\
---\end{array}$ & $\begin{array}{l}--- \\
\cdots- \\
---\end{array}$ & $\begin{array}{l}4 \times 10^{-11} \\
2.3 \times 10^{-11} \\
2.5 \times 10^{-11} \\
6 \times 10^{-11}\end{array}$ & [19] \\
\hline $\begin{array}{c}7050-\mathrm{UA} \text { (T3) } \\
7050-\mathrm{PA} \text { (T6) } \\
\text { 7050-UA (T74) } \\
\text { Low Cu "PA" } \\
\text { Low Cu OA }\end{array}$ & $\begin{array}{l}150-250 \\
150-400 \\
150-400 \\
150-250 \\
150-250 \\
\end{array}$ & $\begin{array}{l}\text { Isothermal } \\
\text { Desorption }\end{array}$ & $\begin{array}{l}5.49 \times 10^{-9} \\
2.24 \times 10^{-9} \\
1.70 \times 10^{-7} \\
2.65 \times 10^{-9} \\
3.24 \times 10^{-9}\end{array}$ & $\begin{array}{l}15.8 \pm 5.0 \\
16.1 \pm 4.2 \\
32.7 \pm 6.7 \\
14.2 \pm 2.5 \\
14.2 \pm 3.2\end{array}$ & $\begin{array}{l}9.33 \times 10^{-12} \\
3.37 \times 10^{-12} \\
3.15 \times 10^{-13} \\
8.59 \times 10^{-12} \\
1.05 \times 10^{-11}\end{array}$ & $\begin{array}{l}\text { Present } \\
\text { Work }\end{array}$ \\
\hline $\begin{array}{l}\mathrm{Al}+0.02 \mathrm{Li} \\
\mathrm{Al}+0.26 \mathrm{Li} \\
\mathrm{Al}+1.12 \mathrm{Li} \\
\end{array}$ & $\begin{array}{l}186-252 \\
276-381 \\
381-480 \\
\end{array}$ & $\begin{array}{l}\text { Tritium concentration } \\
\text { profile analysis }\end{array}$ & $\begin{array}{l}8.5 \times 10^{-9} \\
9.3 \times 10^{-9} \\
5.3 \times 10^{-9} \\
\end{array}$ & $\begin{array}{l}43.9 \pm 14.8 \\
48.5 \pm 15.0 \\
62.7 \pm 13.8 \\
\end{array}$ & $\begin{array}{l}1.3 \times 10^{-16^{*}} \\
2.1 \times 10^{-17} \\
3.5 \times 10^{-20} \\
\end{array}$ & [22] \\
\hline $\begin{array}{l}\mathrm{Al}+1 \text { wt. } \% \mathrm{Li} \\
\mathrm{Al}+2 \mathrm{wt} \% \mathrm{Li} \\
\mathrm{Al}+3 \mathrm{wt} . \% \mathrm{Li}\end{array}$ & $\begin{array}{l}250-600 \\
325-600 \\
325-600\end{array}$ & $\begin{array}{l}\text { Isothermal } \\
\text { Desorption }\end{array}$ & $\begin{array}{l}2.34 \times 10^{-8} \\
1.83 \times 10^{-8} \\
6.66 \times 10^{-8}\end{array}$ & $\begin{array}{l}18.98 \\
18.12 \\
29.32\end{array}$ & $\begin{array}{c}9.67 \times 10^{-12} \\
1.08 \times 10^{-11} \\
3.94 \times 10^{-13}\end{array}$ & [16] \\
\hline
\end{tabular}

" indicates a value extrapolated from high temperature data 


\section{Figure Captions}

Figure 1. Orthogonal metallographic views of the $A A 7050$ (left) and low copper material (right) showing the pancake shaped grain structure. Keller's + Graff and Sargent's etchants.

Figure 2. Schematic illustration of how SIMS, NRA, and TDS measurements were made on different regions of the crack wake. The left hand sketch shows the approximate positions of SIMS and NRA depth profiles. The right hand sketch illustrates how regions of the precrack, $H E A C$ crack, and fast fracture region were sectioned from the crack wake for TDS analysis.

Figure 3. Comparison of the hydrogen concentration profiles from unstressed coupons of underaged and overaged AA 7050 with and without the native oxide. The samples were exposed to $90^{\circ} \mathrm{C}, 90 \% \mathrm{RH}$ air.

Figure 4. Comparison of NRA (top) and SIMS (bottom) spectra from crack wakes.

Figure 5. Thermal desorption spectra from crack wakes of AA 7050-UA. Note that the precrack and $H E A C$ regions contain significantly higher hydrogen concentrations than the fast fracture region or a sample taken $1 \mathrm{~mm}$ below the HEAC region.

Figure 6. Summary of hydrogen diffusion data for AA 7050 and the low copper variant of the alloy.

Figure 7. Thermal desorption spectra from peak aged (top) and overaged (bottom) AA 7050. The dashed lines show how the macroscopic hardness changes as the alloy is heated at a rate of $10^{\circ} \mathrm{C} /$ minute. These results illustrate the thermal instability of the microstructure during the TDS heating cycle.

Figure 8. Hydrogen absorption kinetics from freshly bared $A A 7050$ exposed to $90^{\prime \prime} \mathrm{C}, 90 \% \mathrm{RH}$ air. Note that the underaged and overaged data fall on the same curve fit.

Figure 9. Comparison of the change in the apparent activation energy for stage II crack growth and for hydrogen diffusion. Note that the change for diffusion and crack growth is approximately equal $(\sim 16 \mathrm{~kJ} / \mathrm{mol})$ for the copper bearing AA 7050 while little change is observed for the low copper alloy. 


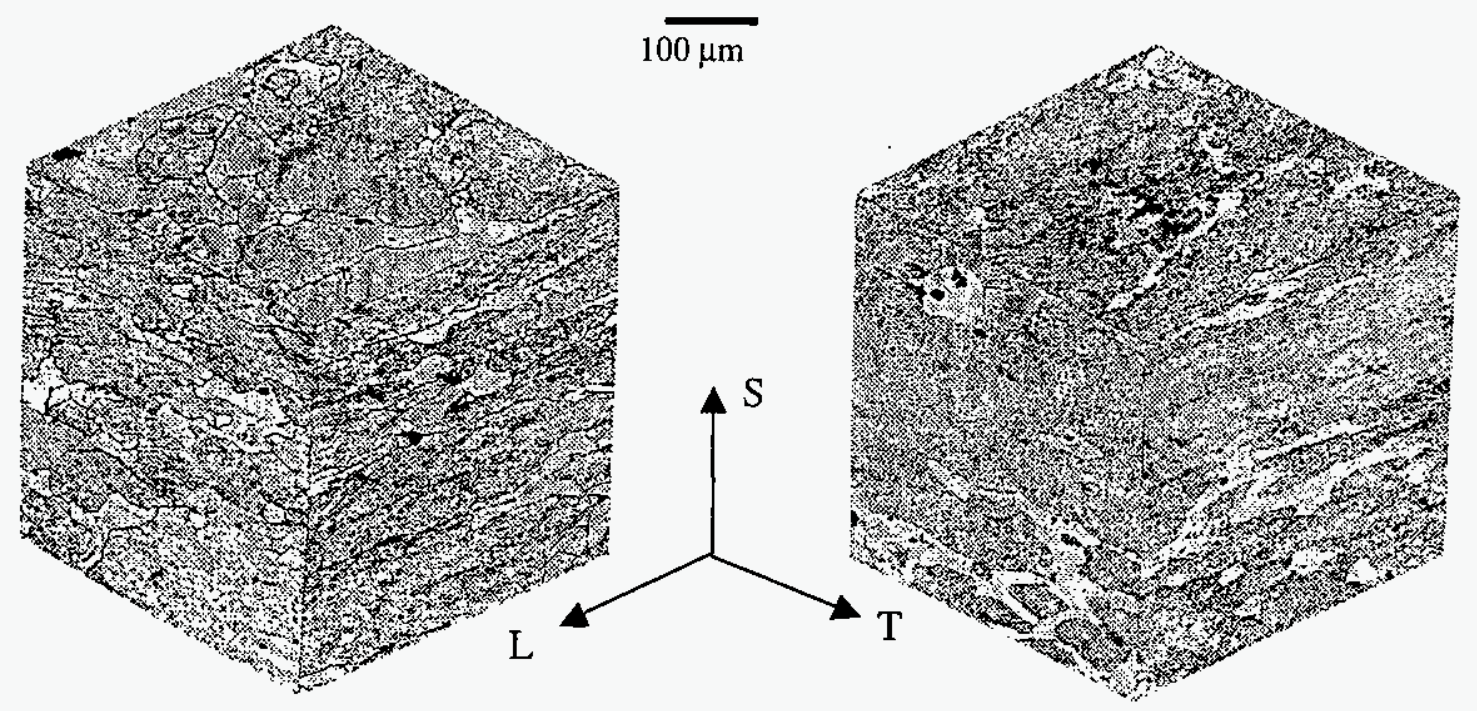

Figure 1. Orthogonal metallographic views of the AA 7050 (left) and low copper material (right) showing the pancake shaped grain structure. Keller's + Graff and Sargent's etchants.
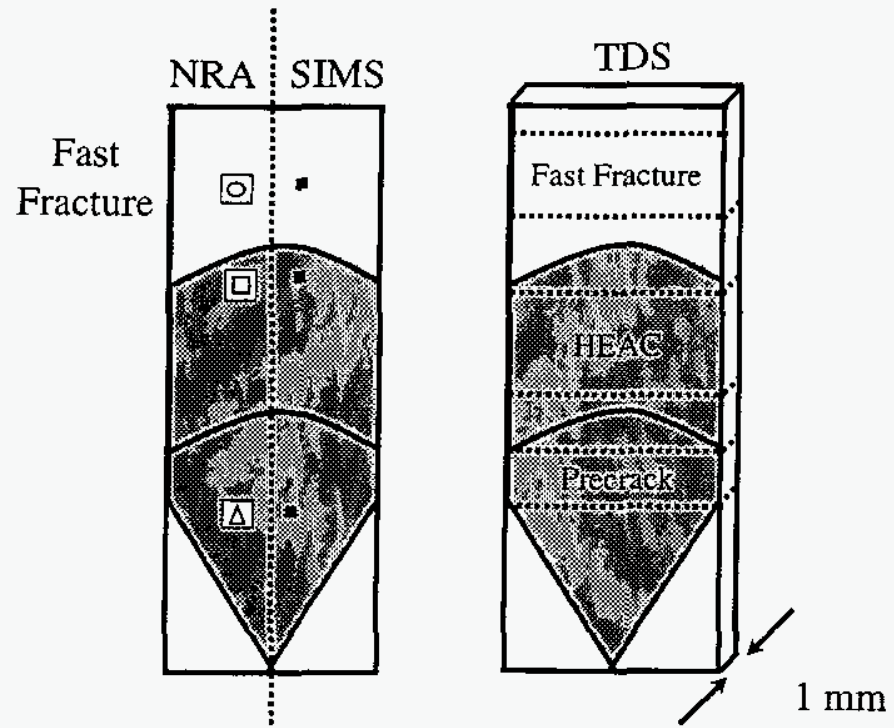

Figure 2. Schematic illustration of how SIMS, NRA, and TDS measurements were made on different regions of the crack wake. The left hand sketch shows the approximate positions of SIMS and NRA depth profiles. The right hand sketch illustrates how regions of the precrack, HEAC crack, and fast fracture region were sectioned from the crack wake for TDS analysis. 


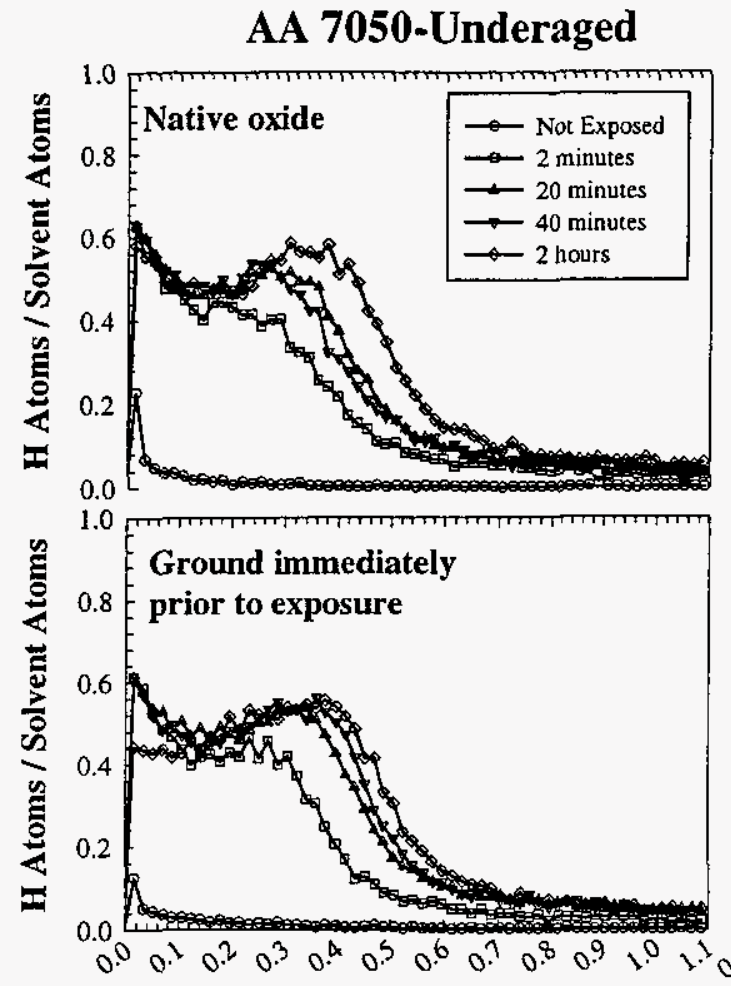

Distance from Surface (microns)
AA 7050-Overaged
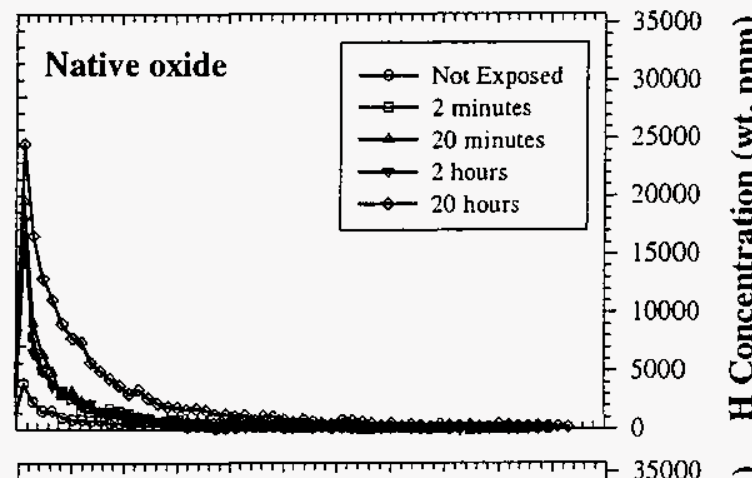

Ground immediately

prior to exposure

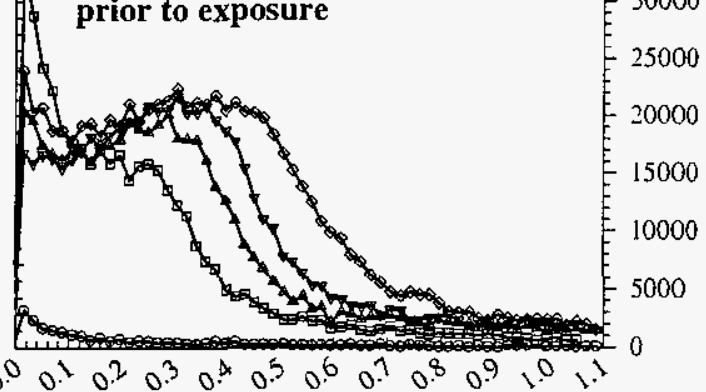

Distance from Surface (microns)

Figure 3. Comparison of the hydrogen concentration profiles from unstressed coupons of underaged and overaged $A A 7050$ with and without the native oxide. The samples were exposed to $90^{\circ} \mathrm{C}, 90 \%$ RH air. 

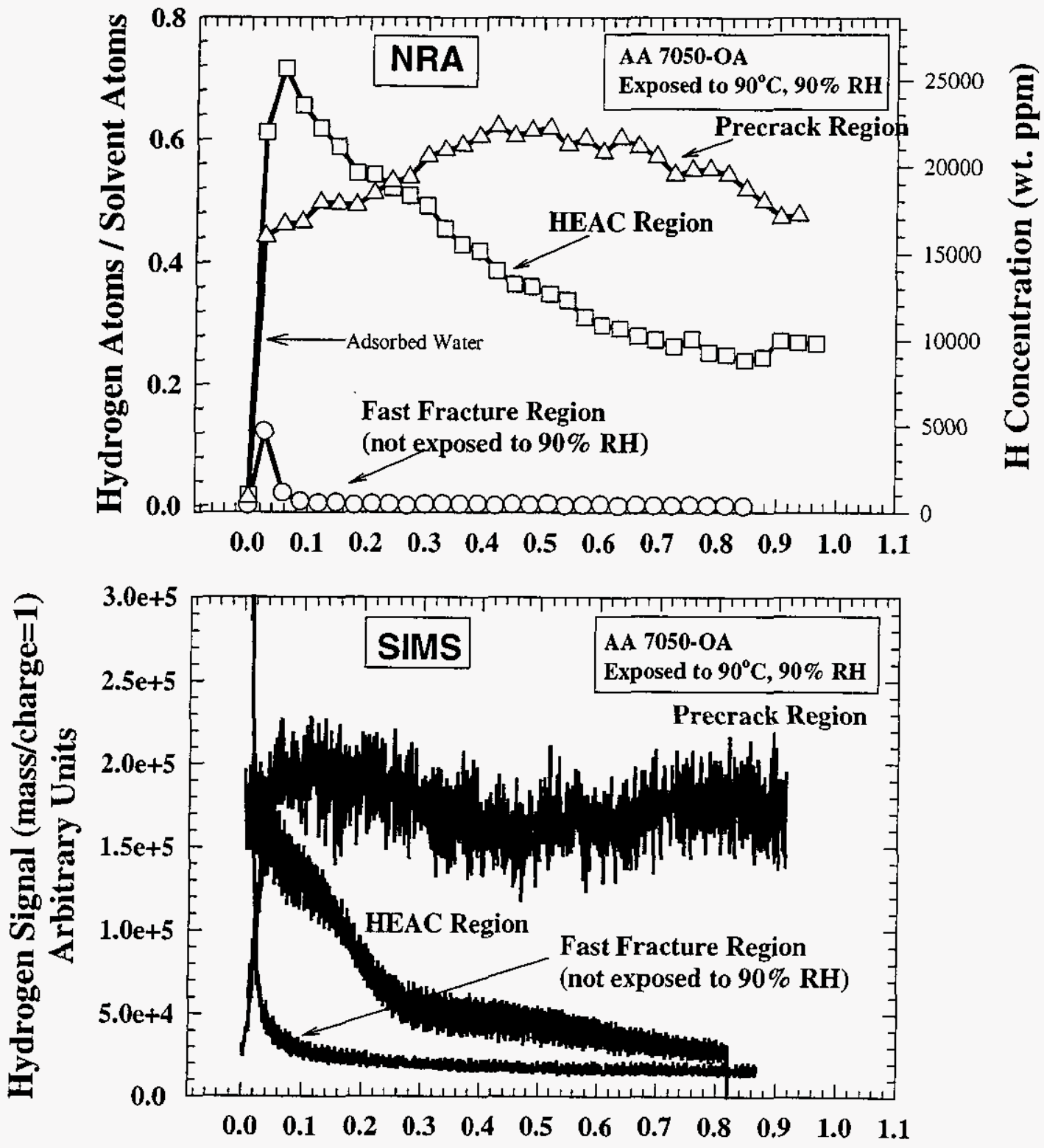

Denth from Fracture Surface (microns)

Figure 4. Comparison of NRA (top) and SIMS (bottom) spectra from crack wakes. 

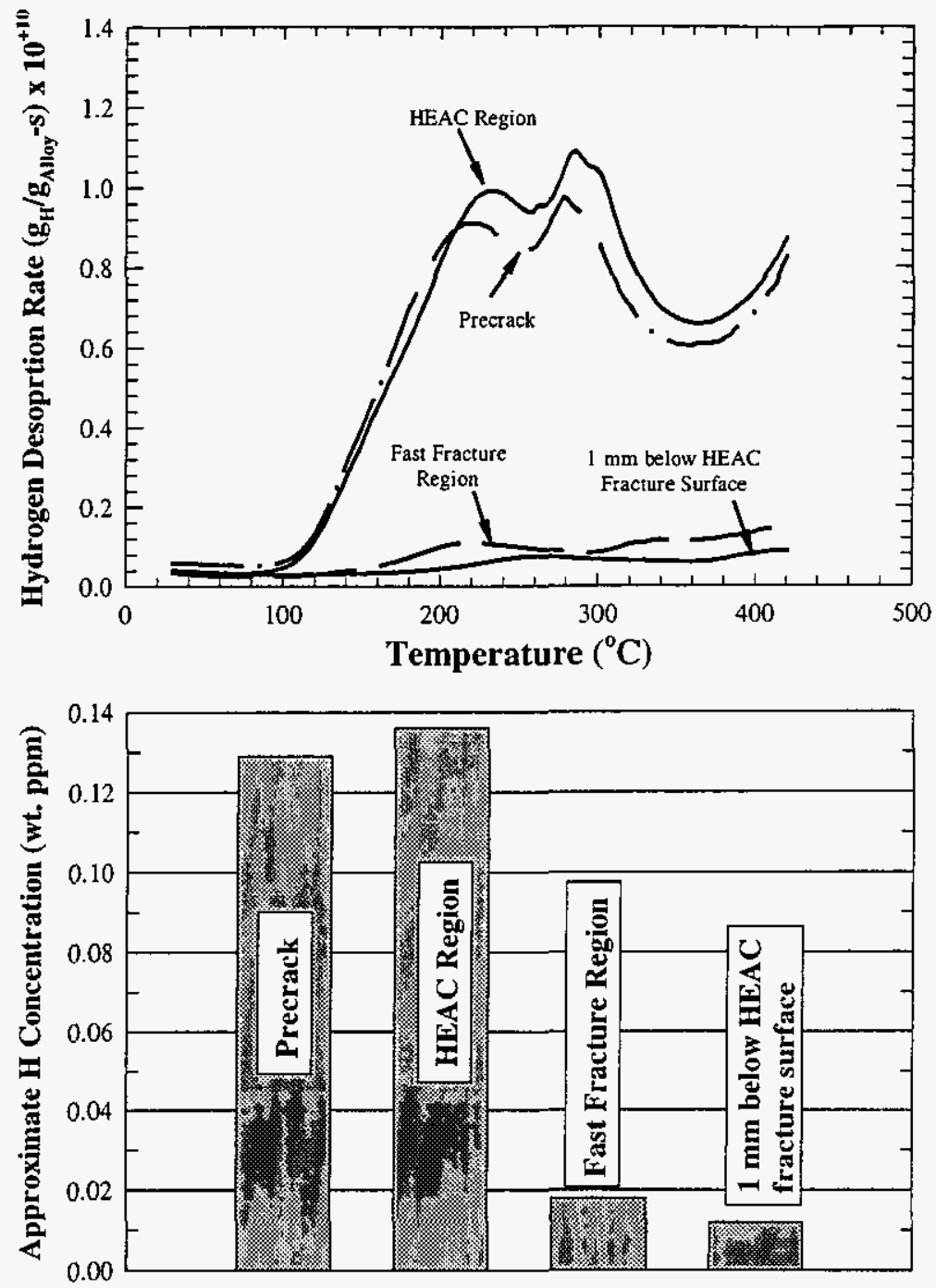

Figure 5. Thermal desorption spectra from crack wakes of AA 7050-UA. Note that the precrack and $H E A C$ regions contain significantly higher hydrogen concentrations than the fast fracture region or a sample taken $1 \mathrm{~mm}$ below the HEAC region. 


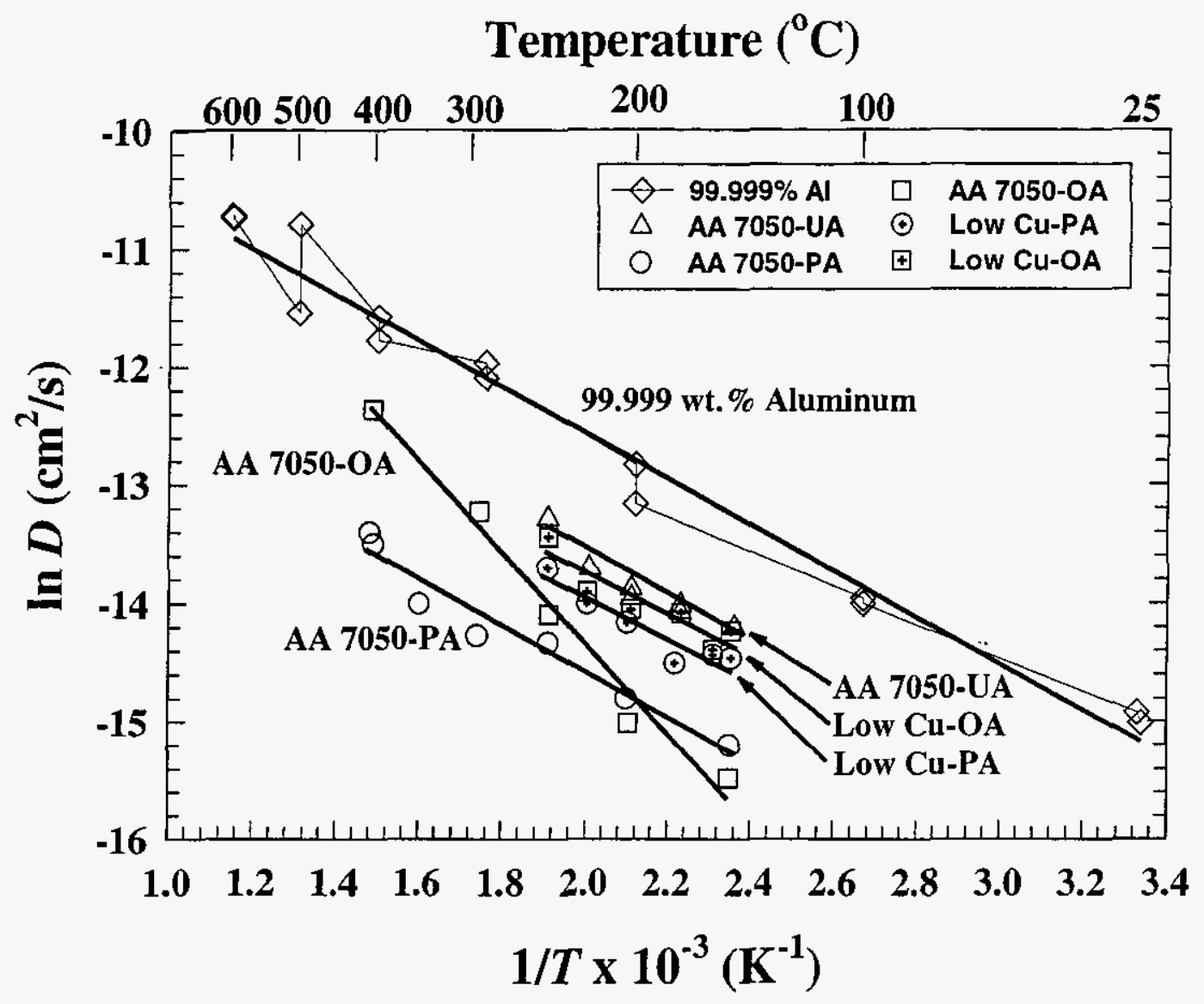

Figure 6. Summary of hydrogen diffusion data for AA 7050 and the low copper variant of the allow.

16 
$7050 \mathrm{PA}$, exposed to $40^{\circ} \mathrm{C}, 90 \%$ humidity air, $188 \mathrm{hrs}$

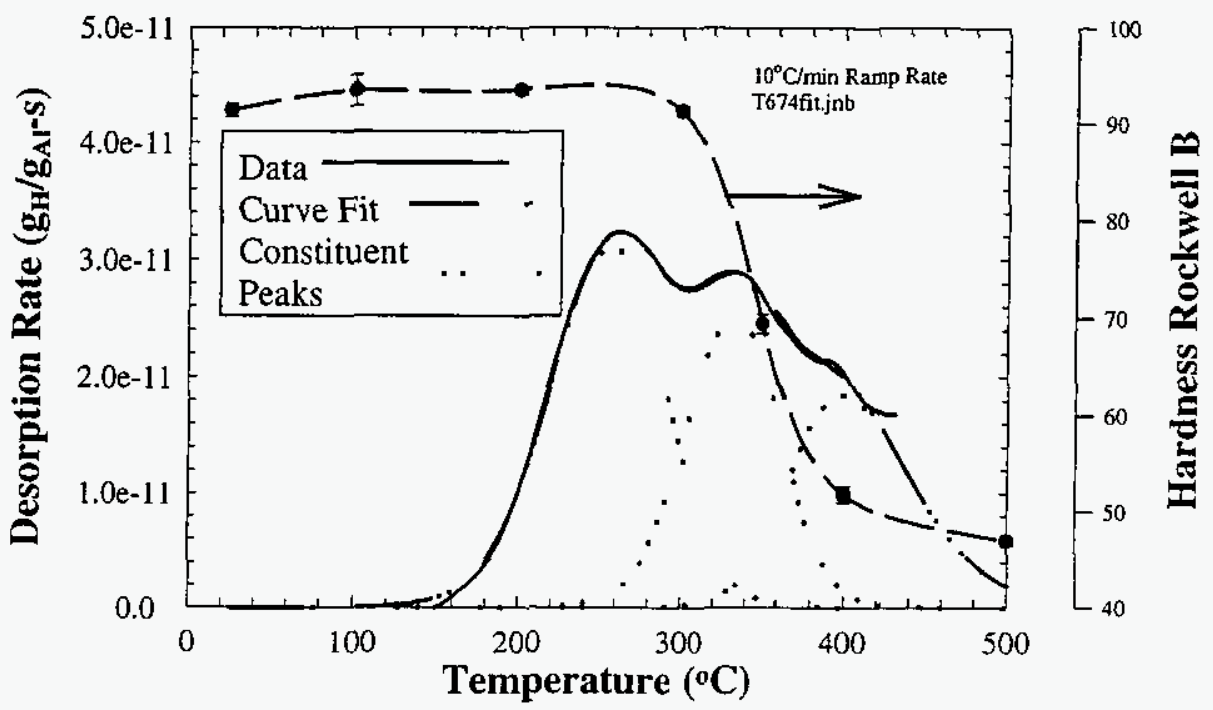

$7050 \mathrm{OA}$, exposed to $40^{\circ} \mathrm{C}, 90 \%$ humidity air, $188 \mathrm{hrs}$

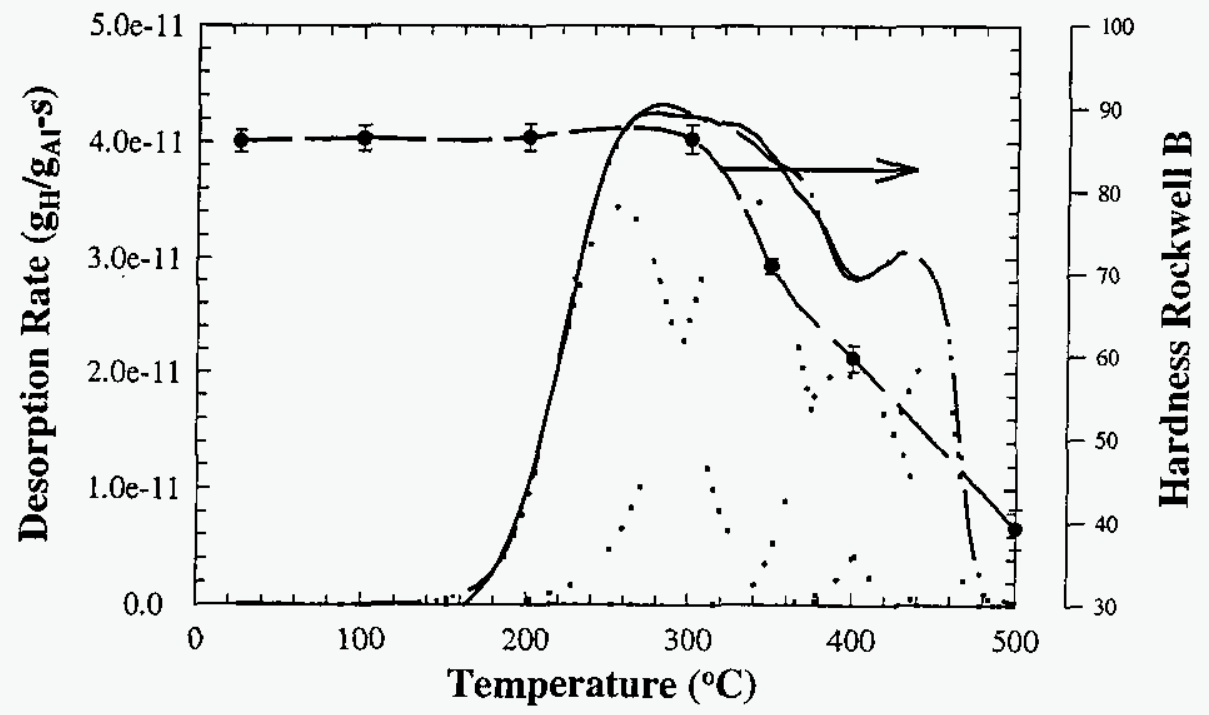

Figure 7. Thermal desorption spectra from peak aged (top) and overaged (bottom) AA 7050. The dashed lines show how the macroscopic hardness changes as the alloy is heated at a rate of $10^{\circ} \mathrm{C}$ minute. These results illustrate the thermal instability of the microstructure during the TDS heating cycle. 


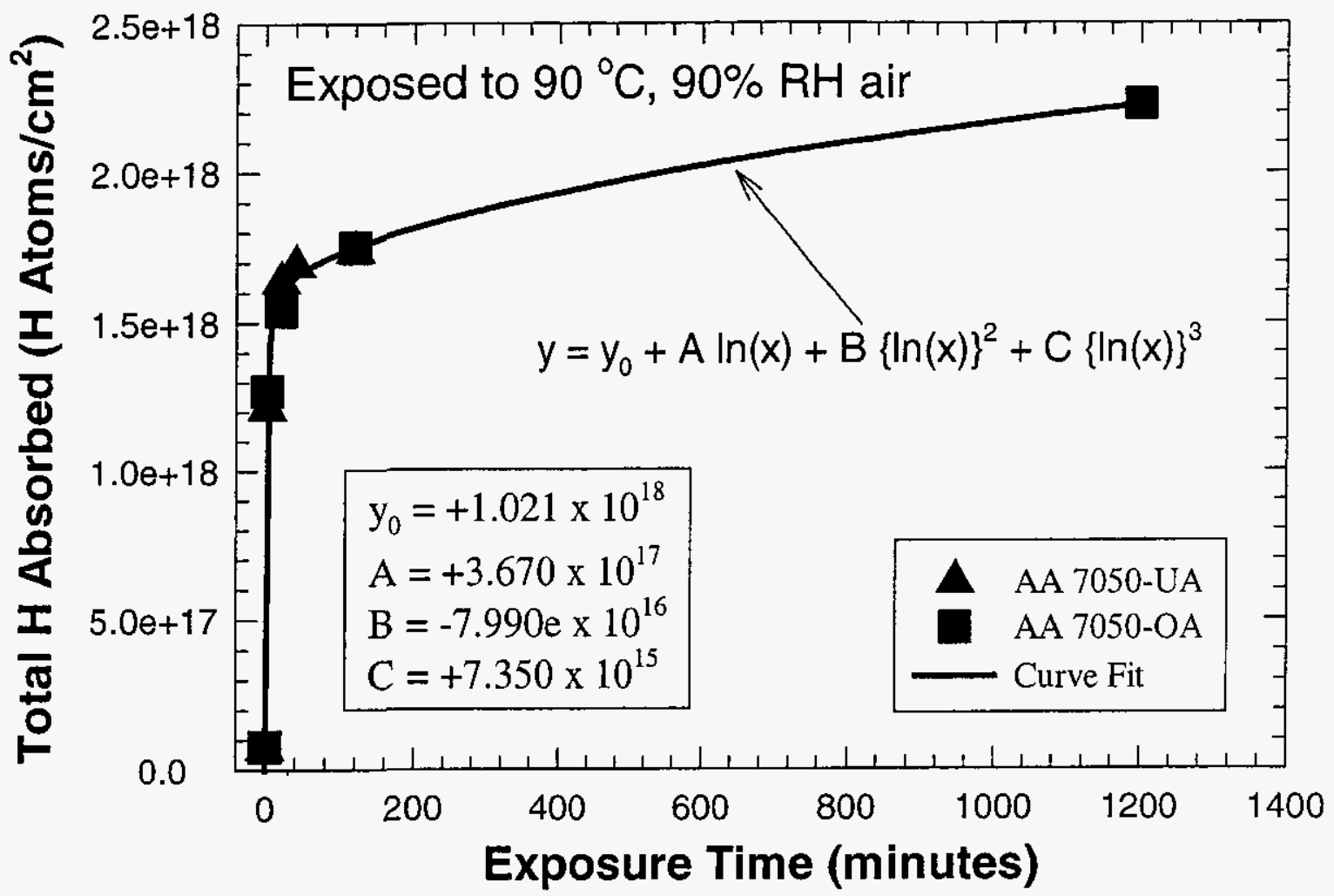

Figure 8. Hydrogen absorption kinetics from freshly bared $A A 7050$ exposed to $90^{\circ} \mathrm{C}, 90 \%$ RH air. Note that the underaged and overaged data fall on the same curve fit. 


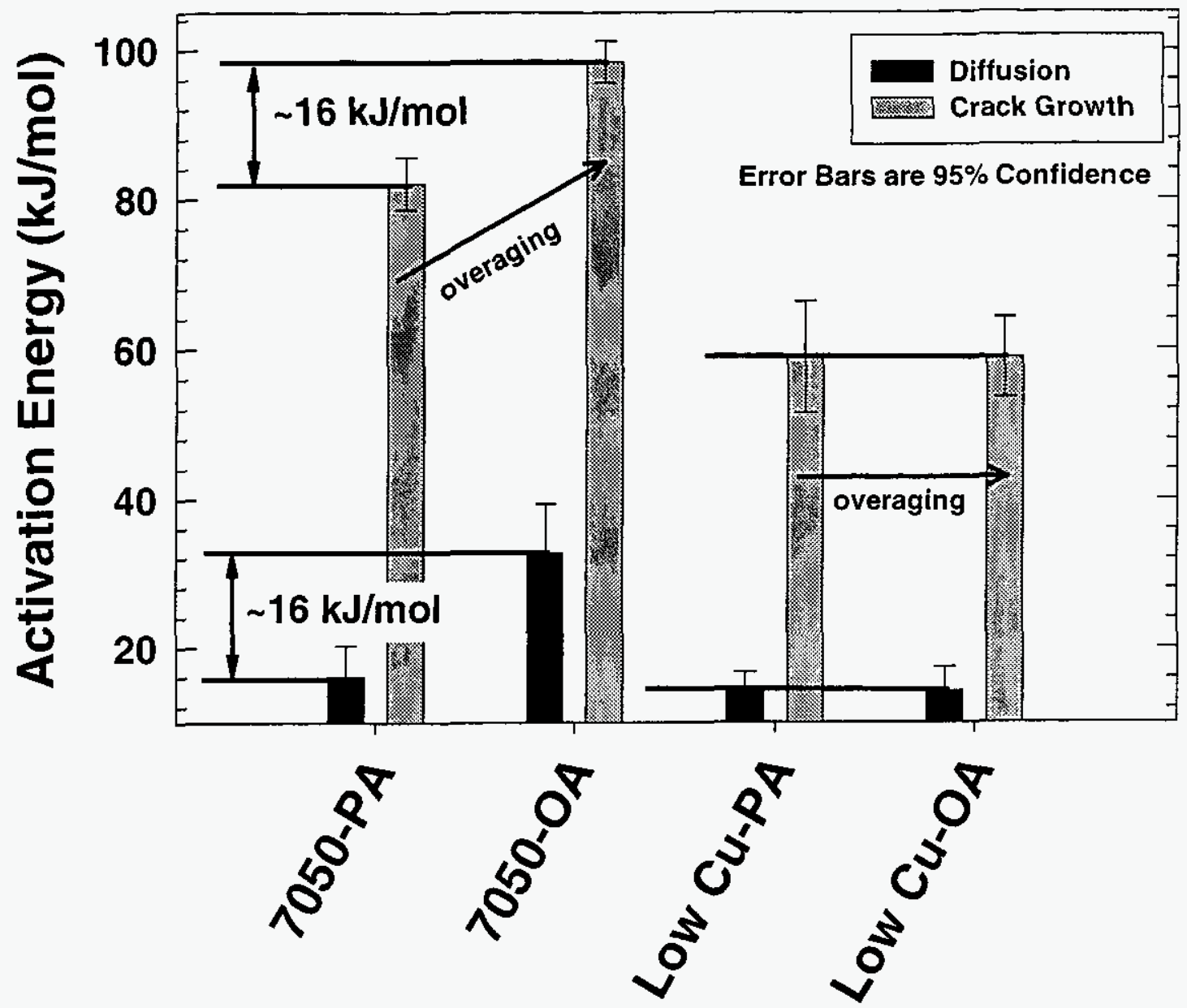

Figure 9. Comparison of the change in the apparent activation energy for stage II crack growth and for hydrogen diffusion. Note that the change for diffusion and crack growth is approximately equal $(\sim 16 \mathrm{~kJ} / \mathrm{mol})$ for the copper bearing $A A 7050$ while little change is observed for the low copper alloy. 